\title{
NOTE
}

\section{Reinvestigation of the structure of 1-aminocyclohexane-1-carboxylic acid hydrochloride $\left(\mathrm{C}_{7} \mathrm{H}_{14} \mathrm{ClNO}_{2}\right)^{*}$}

\author{
K. K. CHACKO AND R. SRINIVASAN \\ Centre of Advanced Study in Physics, \\ University of Madras, Guindy Campus, Madras-600025, India \\ and \\ R. ZAND \\ Biophysics Research Division \\ University of Michigan, Ann Arbor, U.S.A.
}

(Received March 24, 1975)

The title compound, reported earlier by Chacko et al. (1971) in the noncentric space group $P 2_{1}$, is refined in the centrosymmetric space group $P 2_{1} / m$, with the same observed intensity data, to an $R$-index of 0.113 . The structural features and esd's in parameters show marked improvement in the centrosymmetric space group. However, it is interesting to note that some of the atoms in the previous noncentric refinement show highly significant deviations from higher symmetry.

The relevant crystal data are the same as reported earlier by Chacko et al. (1971), except that the structure is reanalyzed in the space group $P 2_{1} / m$ with $Z=2$. During the structure investigation of the hydrobromide derivative of 4-amino-4-carboxylthiapyran (structurally very similar to the title compound except that the methylene group at the $\mathrm{C}(4)$ position of the cyclohexane is replaced by sulfur), it was found that the structure refined only in $P 2_{1} / m$ to

* Contribution No. 400 from the Centre of Advanced Study in Physics, University of Madras, Guindy Campus, Madras-600025, India.

1976 Plenum Publishing Corporation, 227 West 17 th Street, New York, N.Y. 10011. No part of this publication may be reproduced, stored in a retrieval system, or transmitted, in any form or by any means, electronic, mechanical, photocopying, microfilming, recording, or otherwise, without written permission of the publisher. 
give meaningful structural features (Chacko et al., 1975). This led us to reanalyze the title compound in the space group $P 2_{1} / m$. The centrosymmetric space group demands that the molecule has a mirror plane which coincides with the space group mirror at $y=\frac{1}{4}$. The molecule could be expected to have a mirror plane passing through the carboxyl group, $\mathrm{N}, \mathrm{C}(1)$ and $\mathrm{C}(4)$ atoms. In order to prove the correctness of the space group* $P 2_{1} / \mathrm{m}$, the Patterson of the structure was carefully analyzed at sections close to $V=0$ in order to locate peaks corresponding to the chlorine-light atom vector interactions for all those atoms which necessarily fall on the mirror plane for the space group $P 2_{1} / m$ but which do not in $P 2_{1}$, as given in our earlier report [the $C(4), O(2)$ and $O(1)$ atoms show deviations from the $y=\frac{1}{4}$ plane of $0.24,0.22$ and $0.14 \AA$ respectively]. For all atoms, the chlorinelight atom vector interactions (clearly seen in the Patterson analysis, without overlap) showed peak maxima on the section $V=0$, which unequivocally established the correctness of the space group $P 2_{1} / \mathrm{m}$. [The same Patterson analysis was carried out in the structure of 4-amino-4-carboxylthiapyran hydrobromide (Chacko et al., 1975), which clearly indicated that its structure also belonged to the centrosymmetric space group $P 2_{1} / \mathrm{m}$.]

Refinement was carried out in the space group $P 2_{1} / m$ under circumstances reported earlier [with the same weighting scheme and with anomalous dispersion correction factor $\left(\Delta f^{\prime}\right)$ and anisotropic thermal parameters for the chlorine atom] giving an $R$-index of 0.13 , which is larger than what has been reported earlier for the noncentric space group $P 2_{1}(R=0.109)$. The increase in $R$-index for the space group $P 2_{1} / m$ is probably justified by the constraint in the refinement. The standard deviations in coordinates at $R=0.13$ showed good improvement compared to the earlier report. The structure was refined further with anisotropic parameters for all atoms to an $R$-index of 0.113 Hydrogens were fixed theoretically and were included in the structure factor, but were not refined. The final positional parameters given in Table $1 a \dagger$ show much better standard deviations than those reported earlier. Table $1 b$ gives the hydrogen atom coordinates. It is interesting to note that the esd's in positions calculated from the full-matrix, least-squares refinement in the noncentric space group show that some of the atoms [in particular $\mathrm{C}(4)$ and $O(2)]$ have highly significant deviations from higher symmetry (the mean deviations of atoms from higher symmetry is about $0.14 \AA$ ).

The individual bond lengths and angles given in Table 2 show good improvement and compare better with standard values. For instance, one of the $\mathrm{C}-\mathrm{C}$ bonds in the previous report $[\mathrm{C}(5)-\mathrm{C}(6)]$ of $1.569^{\circ}$ and two of the

* Though statistical tests could in principle be applied to distinguish between the space groups $P 2{ }_{1}$ and $P 2{ }_{1} / m$, no theoretical values are available for the present situation for comparison-namely, a crystal with both heavy atoms and psuedosymmetry. Hence, statistical tests were not tried.

$\dagger$ For obvious reasons, the atom numbered $\mathrm{C}(5), \mathrm{C}(6)$ and $\mathrm{C}(7)$ in the earlier report are represented here as $\mathrm{C}\left(3^{\prime}\right), \mathrm{C}\left(2^{\prime}\right)$ and $\mathrm{C}(5)$ atoms respectively. 

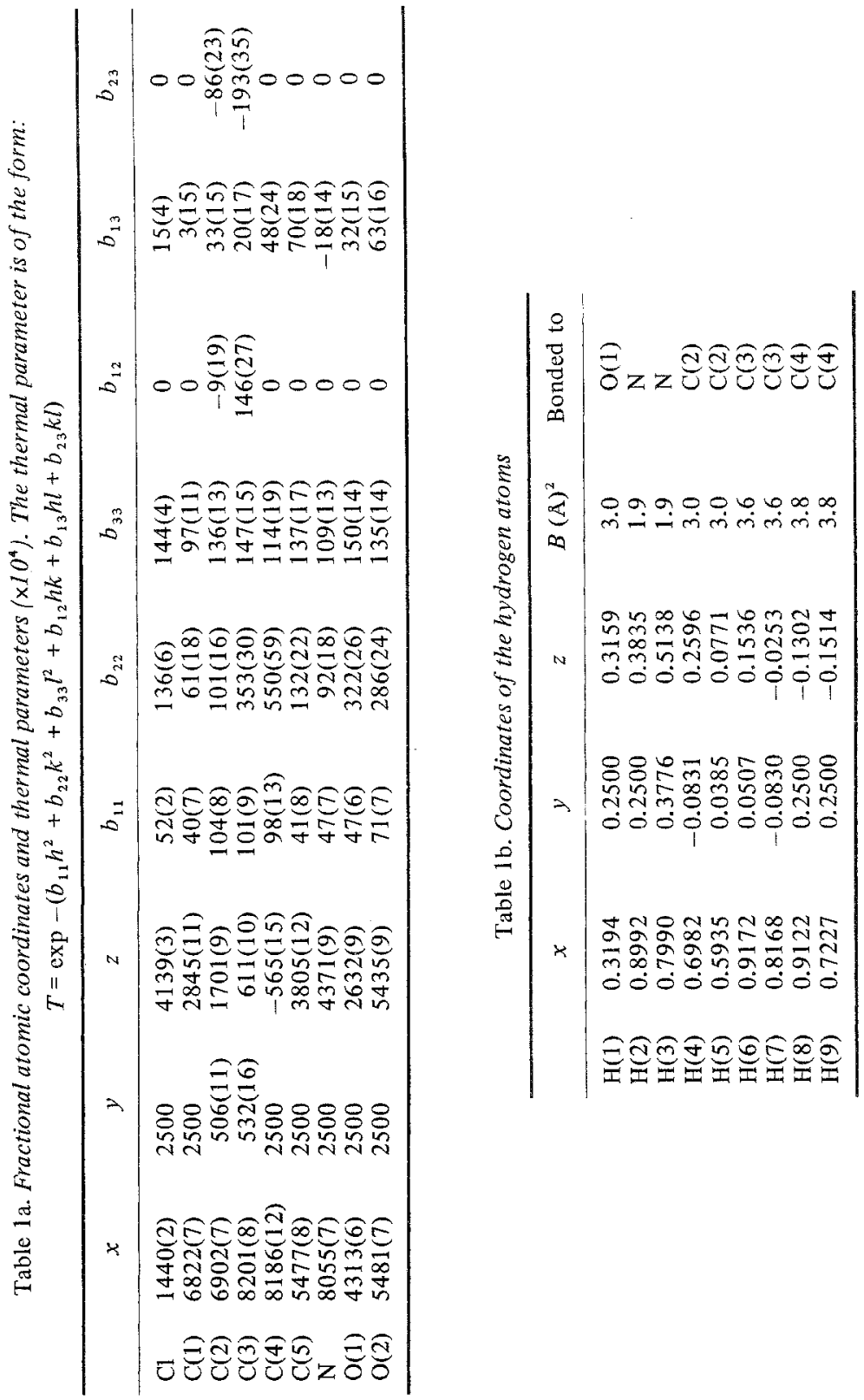
Table 2. Bond lengths $(\AA)$ and angles (deg)

\begin{tabular}{llll}
\hline \multicolumn{2}{c}{ Bond length } & \multicolumn{2}{c}{ Bond angle } \\
\hline $\mathrm{C}(1)-\mathrm{C}(2)$ & $1.538(9)$ & $\mathrm{C}(1)-\mathrm{C}(2)-\mathrm{C}(3)$ & $111.6(6)$ \\
$\mathrm{C}(2)-\mathrm{C}(3)$ & $1.530(12)$ & $\mathrm{C}(2)-\mathrm{C}(3)-\mathrm{C}(4)$ & $110.4(7)$ \\
$\mathrm{C}(3)-\mathrm{C}(4)$ & $1.530(11)$ & $\mathrm{C}(3)-\mathrm{C}(4)-\mathrm{C}\left(3^{\prime}\right)$ & $110.8(7)$ \\
$\mathrm{C}(1)-\mathrm{C}(5)$ & $1.511(12)$ & $\mathrm{C}(2)-\mathrm{C}(1)-\mathrm{C}\left(2^{\prime}\right)$ & $112.2(6)$ \\
$\mathrm{C}(1)-\mathrm{N}$ & $1.530(12)$ & $\mathrm{C}(2)-\mathrm{C}(1)-\mathrm{C}(5)$ & $110.5(6)$ \\
$\mathrm{C}(5)-\mathrm{O}(1)$ & $1.322(11)$ & $\mathrm{C}(2)-\mathrm{C}(1)-\mathrm{N}$ & $109.3(6)$ \\
$\mathrm{C}(5)-\mathrm{O}(2)$ & $1.206(11)$ & $\mathrm{C}(5)-\mathrm{C}(1)-\mathrm{N}$ & $104.9(5)$ \\
& & $\mathrm{C}(1)-\mathrm{C}(5)-\mathrm{O}(1)$ & $111.4(5)$ \\
& & $\mathrm{C}(1)-\mathrm{C}(5)-\mathrm{O}(2)$ & $123.7(6)$ \\
& & $\mathrm{C}(1)-\mathrm{C}(5)-\mathrm{O}(2)$ & $124.9(6)$ \\
\hline
\end{tabular}

$\mathrm{C}-\mathrm{C}-\mathrm{C}$ bond angles of $106.7^{\circ} \quad[\mathrm{C}(2)-\mathrm{C}(3)-\mathrm{C}(4)]$ and $115.8^{\circ}$ $[\mathrm{C}(4)-\mathrm{C}(5)-\mathrm{C}(6)]$ of the cyclohexane ring (which show large deviations from the expected values of $1.533 \AA$ in bond length and $111.5^{\circ}$ in bond angle) show marked improvement in the centrosymmetric space group, where the corresponding bond length $[C(2)-C(3)]$ and angle $[C(2)-C(3)-C(4)]$ have values of $1.530 \AA$ and $110.4^{\circ}$ respectively. The mean $\mathrm{C}-\mathrm{C}$ bond length of $1.533 \AA$ of the cyclohexane ring is the same as that reported for $n$-alkanes (Bartell and Kohl, 1963) and the mean $\mathrm{C}-\mathrm{C}-\mathrm{C}$ bond angle of $111.3^{\circ}$ agrees very well with $111.5^{\circ}$ for the cyclohexane chair conformation (Bixon and Lifson, 1967). Torsion angle about bonds of the cyclohexane ring are given in Table 3, which indicate that its conformation, as is to be expected, is a much

Table 3. Torsion angles (deg) about bonds of the cyclohexane ring

\begin{tabular}{lr}
\hline $\mathrm{C}\left(2^{\prime}\right)-\mathrm{C}(1)-\mathrm{C}(2)-\mathrm{C}(3)$ & $52.3(7)$ \\
$\mathrm{C}(1)-\mathrm{C}(2)-\mathrm{C}(3)-\mathrm{C}(4)$ & $-55.3(8)$ \\
$\mathrm{C}(2)-\mathrm{C}(3)-\mathrm{C}(4)-\mathrm{C}\left(3^{\prime}\right)$ & $58.8(9)$ \\
Mean absolute deviation & \\
taking Bixon and Lifson's & \\
value as Standard: & $2.4^{\circ}$ \\
\hline
\end{tabular}

less distorted chair than that reported earlier, the theoretical values of the torsion angle for chair conformation being $\pm 54.7^{\circ}$ (Bixon and Lifson, 1967). Judging from the improved structural features, it is evident that the structure has refined in a false least-squares minimum in the noncentric space group reported earlier.

The packing of the structure down $b$ is given in Fig. 1, which shows all the hydrogen bonds. The hydroxyl oxygen atom $O(1)$ forms a hydrogen 


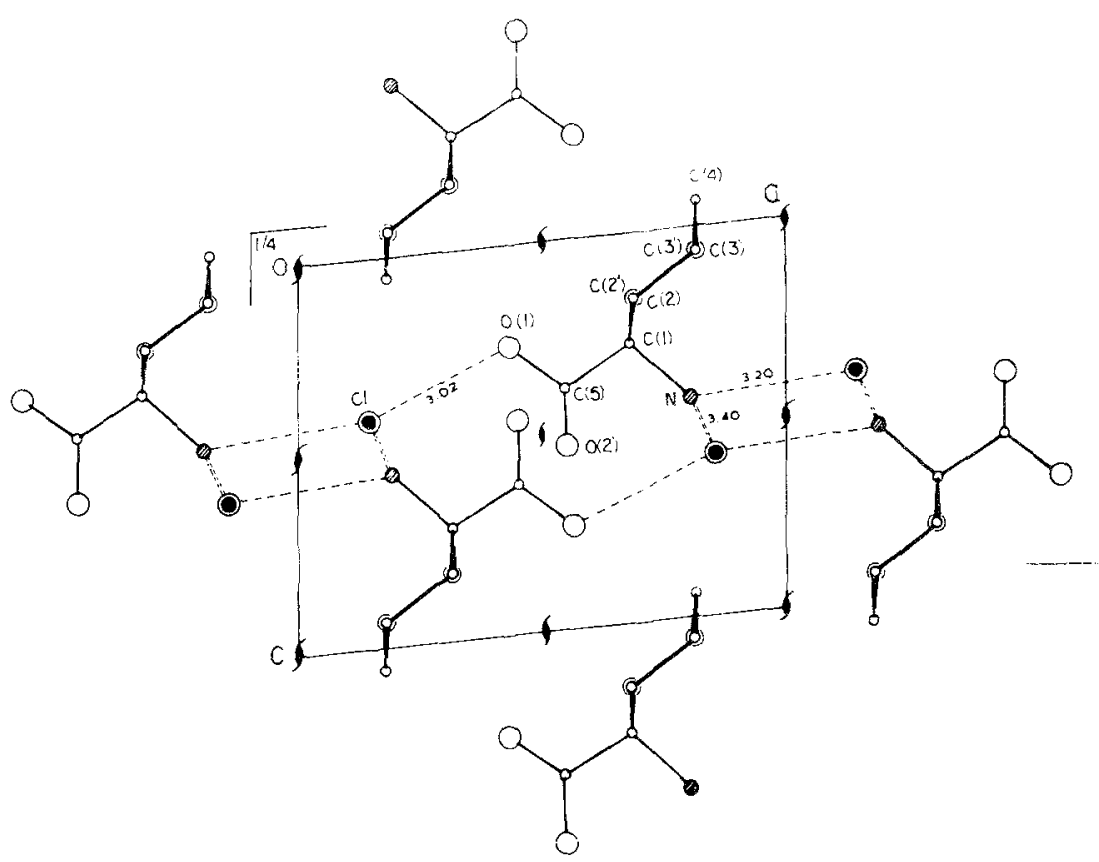

Fig. 1. Packing of the structure down the $b$ axis. All hydrogen bonds are shown.

bond with $\mathrm{Cl}^{-}$of length $3.02 \AA$. One of the hydrogen bonds of the amino nitrogen $\left(\mathrm{NH}_{3}^{+}\right)$is with a translated $\mathrm{Cl}^{-}$along $a$ of length $3.20 \AA$. (The donor and acceptor atoms for these two hydrogen bonds are on the mirror plane itself.) The other two hydrogen bonds of $\mathrm{N}$ are with mirror-related chlorine ions of length $3.40 \AA$. From the nature of the packing and hydrogen bonding scheme also, one can come to the conclusion that the structure would favour the space group $P 2_{1} / m$ rather than $P 2_{1}$.

\section{References}

Bartell, L. S. and Kohl, D. A. (1963) J. Chem. Phys. 39, 3097.

Bixon, M. and Lifson, S. (1967) Tetrahedron, 23, 769.

Chacko, K. K., Bhattacharjee S. K. and Zand, R. (1975) J. Cryst. Mol. Struct. 5, 295.

Chacko, K. K., Srinivasan, R. and Zand, R. (1971) J. Cryst. Mol. Struct. 1, 261.

British Library Lending Division Supplementary Publication No. 60156 contains 6 pages of structure factor tables on 1 microfiche. 